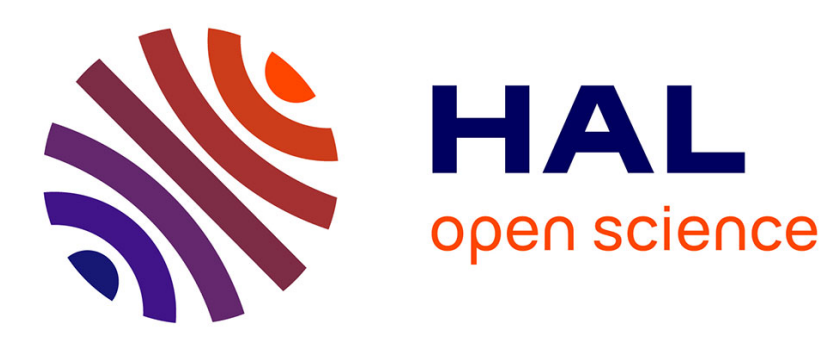

\title{
DC characteristics of gate-all-around (GAA) silicon-on-insulator MOSFETs at cryogenic temperatures
}

\author{
E. Simoen, C. Claeys
}

\section{To cite this version:}

E. Simoen, C. Claeys. DC characteristics of gate-all-around (GAA) silicon-on-insulator MOSFETs at cryogenic temperatures. Journal de Physique IV Proceedings, 1994, 04 (C6), pp.C6-51-C6-56. 10.1051/jp4:1994608 . jpa-00253102

HAL Id: jpa-00253102

https://hal.science/jpa-00253102

Submitted on 1 Jan 1994

HAL is a multi-disciplinary open access archive for the deposit and dissemination of scientific research documents, whether they are published or not. The documents may come from teaching and research institutions in France or abroad, or from public or private research centers.
L'archive ouverte pluridisciplinaire HAL, est destinée au dépôt et à la diffusion de documents scientifiques de niveau recherche, publiés ou non, émanant des établissements d'enseignement et de recherche français ou étrangers, des laboratoires publics ou privés. 


\title{
DC characteristics of gate-all-around (GAA) silicon-on-insulator MOSFETs at cryogenic temperatures
}

E. Simoen and C. Claeys

IMEC, Kapeldreef 75, 3001 Leuven, Belgium

\begin{abstract}
This paper describes the static I-V characteristics at cryogenic temperatures $(77 \mathrm{~K}$ and $4.2 \mathrm{~K}$ ) of so-called dual-gate Silicon-on-Insulator (SOI) MOSFETs, fabricated in the Gateall-Around (GAA) technology. The n-channel devices are characterised by an increase of the threshold voltage and the transconductance upon cooling, which is observed both for the edgechannel component and for the primary drain current. It is shown that the devices suffer less from the hysteresis and transient effects, which have been reported before in standard SOI transistors. For the first time, the occurrence of the back-gate induced Multistable-ChargeControlled-Memory (MCCM) effect in GAA devices is demonstrated at $4.2 \mathrm{~K}$. The p-channel devices on the other hand show specific instabilities at deep cryogenic temperatures, which are related to the unexpected reduction of $I V_{T} \mathrm{~T}$.
\end{abstract}

\section{INTRODUCTION}

Presently so-called dual-gate SOI MOSFETs receive considerable interest. One of their attractive features is the superior static characteristics compared with standard SOI counterparts [1-4]. For instance, the presence of a thin gate at the back of the device, depicted in Fig. 1a yields an increase of the current drive by at least a factor of two. At the same time, the effect of the "low-quality" buried oxide is eliminated, so that these devices hold a strong potential for rad-hard applications [5-7]. Another potential field of applications is for cryogenic electronics circuitry. Standard SOI devices may show undesirable transient and hysteresis effects, as recently reviewed [8]. The subject of this paper therefore is to study the low temperature operation of so-called gate-all-around (GAA) SOI MOSFETs [9], with particular emphasis on $4.2 \mathrm{~K}$ operation.

\section{EXPERIMENTAL}

The devices studied have been processed in a modified $3 \mu \mathrm{m}$ CMOS technology as outlined previously [9]. The substrates used are $125 \mathrm{~mm}$ SIMOX wafers. Only a few additional processing steps are required to fabricate the GAA structure: a cavity is etched underneath the silicon islands (Fig. 1b), which is subsequenltly oxidised. Therefore, both top and bottom of the silicon film are in contact with good quality oxide. $\mathrm{n}$ - and p-channel devices with a gate oxide thickness $t_{\mathrm{ox}}$ of $50 \mathrm{~nm}$ have been fabricated: the final film thickness is $100 \mathrm{~nm}$. The device dimensions are WxL: $3 \mu \mathrm{m} \times 3 \mu \mathrm{m}$, or $4 \mu \mathrm{m} \times 3 \mu \mathrm{m}$. (W is the designed width).

Low temperature measurements are performed using a HP 4145 parameter analyzer. Dual-in-line mounted devices are immersed either in liquid nitrogen or in liquid helium. Input ( $I_{D}-V_{G S}$ ) characteristics are recorded for a drain voltage $\left|V_{D S}\right|=50$ or $100 \mathrm{mV}$. The effect of the back-gate bias 
( $V_{B G}$ ) is investigated by applying a sufficiently positive (n-channel) or negative bias pulse. The occurrence of hysteresis is investigated by comparing a low-high (LH) sweep with a high-low (HL) $V_{G S}$ or $V_{D S}$ sweep. The sweep direction is indicated by arrows in the figures.

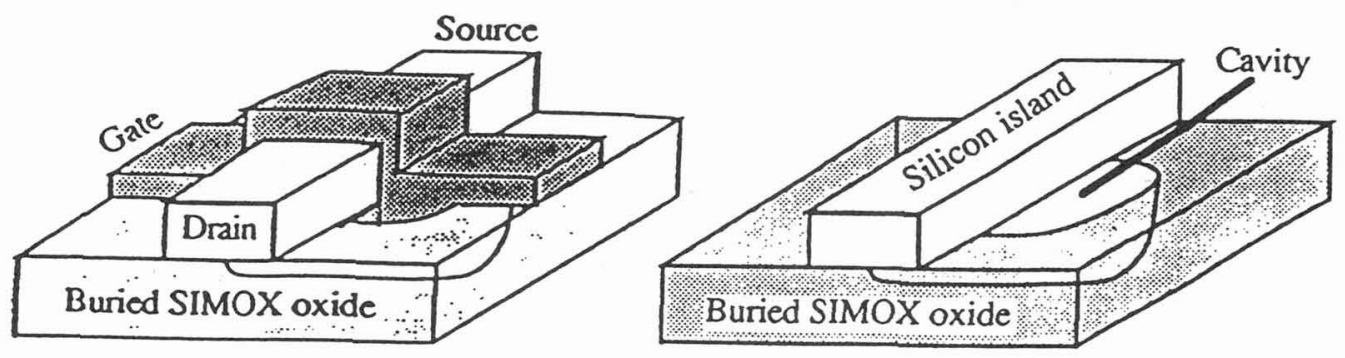

Fig. 1a. Schematical representation of the Gate-Allround SOI MOSFET.
Fig. 1b. The GAA structure is processed in the cavity, which is etched first.

\section{RESULTS AND DISCUSSION}

\subsection{GAA n-MOSFETs}

Typical input curves for a GAA n-MOSFET at the temperatures of interest are shown in Fig. 2a. A clear increase of the subthreshold slope is observed at low temperatures, reaching values which are close to the theoretical limits [9]. An improvement by more than a factor two is observed upon cooling from room temperature down to $4.2 \mathrm{~K}$. The corresponding values of $S=\partial \mathrm{V}_{\mathrm{GS}} / \partial \log \mathrm{I}_{\mathrm{D}}$ are summarised in Table I, together with the threshold voltages $\mathrm{V}_{\mathrm{T}}$ and the maximum transconductance $\mathrm{g}_{\mathrm{mmax}}$. The increase of $\mathrm{V}_{\mathrm{T}}$ and of $\mathrm{g}_{\mathrm{mmax}}$ is as could be expected from theory and is of the same order as for standard SOI n-MOSFETs operated at low temperatures [10-11]. In other words, the transconductance improvement for the dual-gate structures is maintained at cryogenic temperatures.

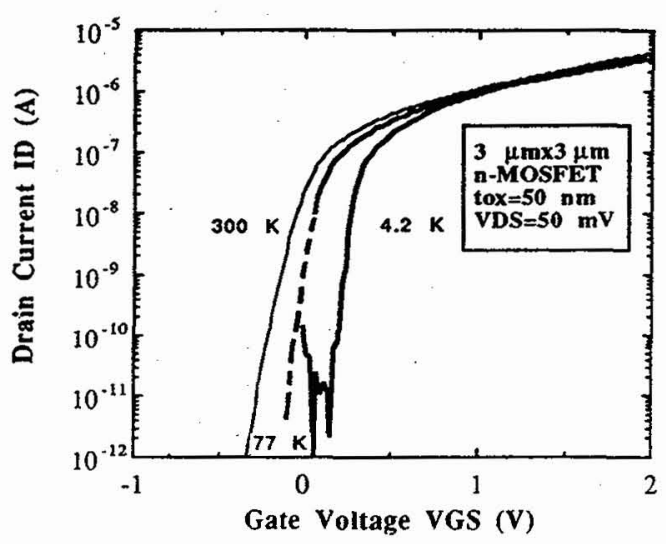

Fig. 2a. Input curves of a GAA n-MOSFET at the temperatures of interest. $V_{D S}=50 \mathrm{mV}$. The curves are registered from low-to-high $\mathrm{V}_{\mathrm{GS}}$.

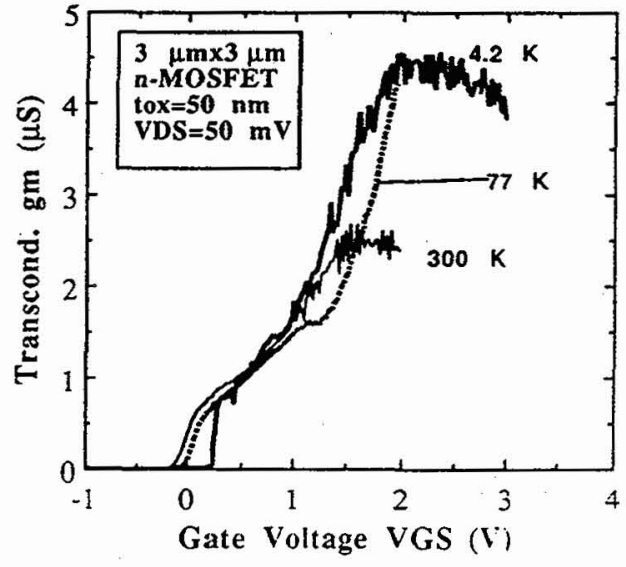

Fig. 2b. Corresponding transconductance. 
One typical feature of the GAA n-MOSFETs is the occurrence of edge conduction (or leakage) along the sides of the device [12], giving rise to a subthreshold $\mathrm{g}_{\mathrm{m}}$ plateau at room temperature (Fig. $2 \mathrm{~b}$ ). This parasitic conductance is preserved upon cooling (Fig. 2b). Its position shifts to higher gate voltages $V_{G S}$, while the plateau amplitude increases roughly proportional to $g_{\operatorname{mmax}}$. The threshold voltage of this parasitic edge conduction can de derived from the so-called double derivative extraction method [13]. This is illustrated in Fig. 3a and $3 b$, where $\partial^{2} I_{D} / \partial v_{G S}^{2}$ is represented as a function of the gate voltage. The corresponding values of the "edge" $\mathrm{V}_{\mathrm{T}}$ are also summarised in Table $\mathrm{I}$. From the data, it is derived that the edge $V_{T}$ is less sensitive to cooling (or to the freeze-out of the Fermi level in the film), than the channel threshold. This is probably due to the large electric fields which exist in the corners of the GAA structure.

It should finally be noted that no kink is observed in the output curves, for the whole temperature range studied.

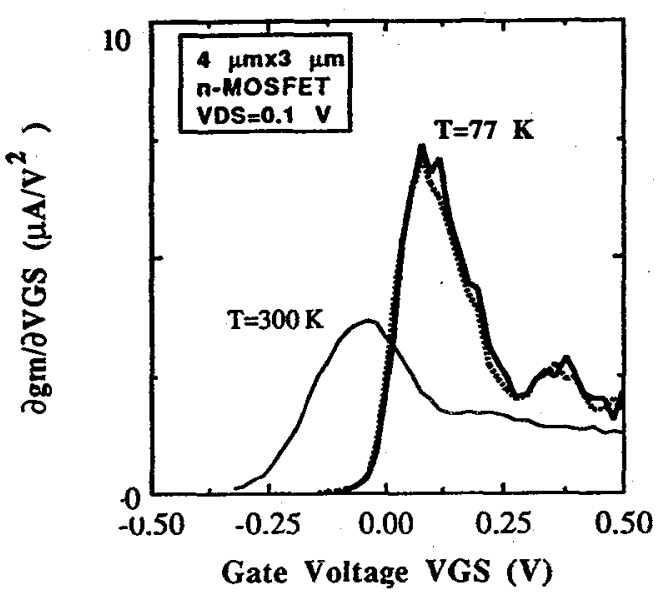

Fig. 3a. Edge conduction $V_{T}$ position as derived from the double derivative method, at $300 \mathrm{~K}$ and $77 \mathrm{~K}$. The dotted line is obtained after a $V_{B G}=+10 \mathrm{~V}$ sweep. No transient effect is observed in this case. $\mathrm{WxL}=4 \mu \mathrm{mx} 3$ $\mu \mathrm{m} . \mathrm{V}_{\mathrm{DS}}=0.1 \mathrm{~V}$.

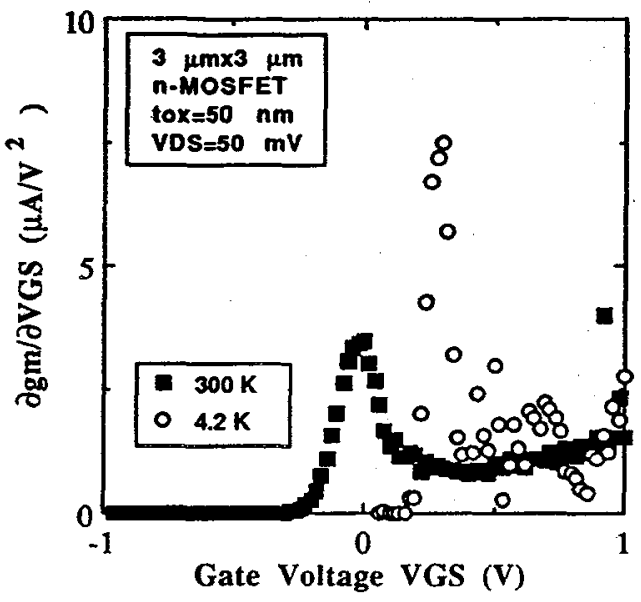

Fig. $3 \mathrm{~b}$. Edge $\mathrm{V}_{\mathrm{T}}$ at $300 \mathrm{~K}$ and at $4.2 \mathrm{~K}$ of a $3 \mu \mathrm{m} \times 3 \mu \mathrm{m}$ GAA $\mathrm{n}-\mathrm{MOSFET}$. The data are summarised in Table $\mathrm{I}$.

Table I. Characteristics of a GAA n-MOSFET at the temperatures studied, in linear operation $\left(V_{D S}=0.1\right.$ V). The data are extracted from initial curves, i.e. immediately after cooling the device. Zero back-gate bias was applied and a LH V $\mathrm{GS}$ sweep was used.

\begin{tabular}{|c|c|c|c|c|}
\hline $\mathrm{T}(\mathrm{K})$ & $\mathrm{V}_{\mathrm{T}}$ (volt) & $\begin{array}{c}\text { Edge } \mathrm{V}_{\mathrm{T}} \\
(\text { volt })\end{array}$ & $\mathrm{S}(\mathrm{mV} / \mathrm{dec})$. & $\begin{array}{c}g_{\operatorname{mmax}} \\
(\mu \mathrm{S})\end{array}$ \\
\hline 300 & 0.66 & -0.040 & 58.4 & 4.9 \\
\hline 77 & 0.85 & +0.080 & 35.0 & 8.1 \\
\hline 4.2 & 1.20 & +0.260 & 24.0 & 8.9 \\
\hline
\end{tabular}




\subsection{Transient and hysteresis}

At $77 \mathrm{~K}$, little hysteresis is observed in the input characteristics, as will be shown in more detail elsewhere [14]. From Fig. 3a it is for instance clear that the edge conduction is hardly affected by a back-gate bias pulse. The front-channel transconductance however reduces markedly, after the application of a positive $V_{B G}$ pulse for instance [14].

For standard SOI MOSFETs the transient/hysteresis effects are much more pronounced at liquid helium temperatures $[11,15,16]$. The transients are believed to be related to the free-carrier capture and slow reemission by the partially frozen-out dopant atoms [15,16]. In general, the depletion region in a MOSFET at deep cryogenic temperatures is far from its steady state, giving rise to pronounced and slow current transients. However, for GAA n-MOSFETs, little hysteresis is observed both in the input (Fig. 4a) and in the output curves. This is a considerable improvement compared with standard SOI components and is a very promising result for the cryogenic operation of these devices.

A special class of metastable behaviour in standard partially depleted SOI MOSFETs gives rise to the socalled MCCM effect [17], which occurs after the application of a proper bias pulse at the back-gate. In fact, similar phenomena occur in accumulation mode devices [18]. Potentially, this effect may give rise to new applications for cryogenic SOI devices. At first sight, one would not expect any influence of the back-gate on the characteristics of a GAA device, since the bottom interface is screened by the gate electrode. However, applying a negative $\mathrm{V}_{\mathrm{BG}}$ gives rise to a clear increase of the $\mathrm{V}_{\mathrm{T}}$, as in Fig. $4 \mathrm{~b}$, i.e., the input curve shifts from position 1 to 2 . This metastable high state relaxes slowly to steady state (curve 3), so that there is again some memory action. Fast restoration of the low state can be achieved for instance by a 'large' drain voltage pulse, during. an output characteristic measurement.

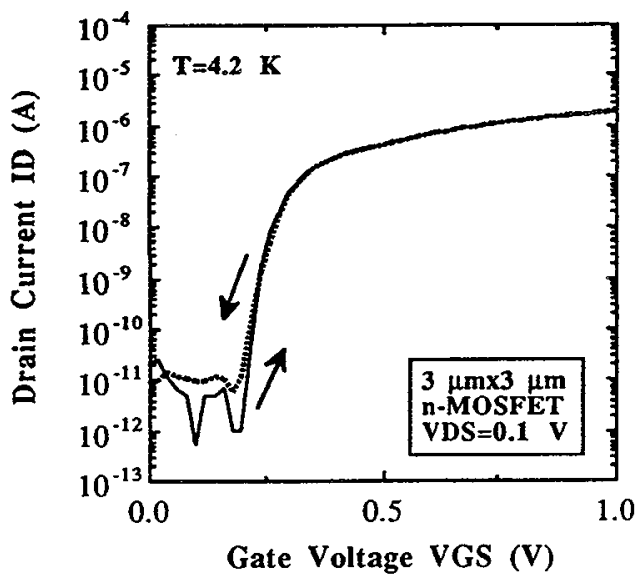

Fig. 4a. Illustration of the absence of hysteresis in linear operation for a $3 \mu \mathrm{mx} 3 \mu \mathrm{m}$ GAA $\mathrm{n}$-MOSFET at $4.2 \mathrm{~K}$. $\mathrm{V}_{\mathrm{DS}}=0.1 \mathrm{~V}$.

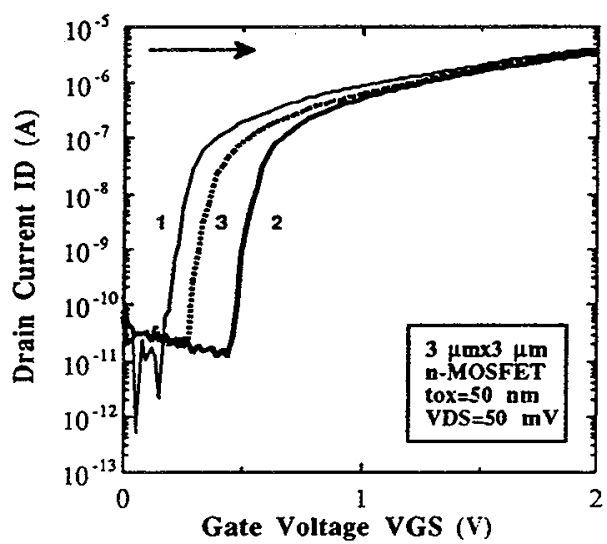

Fig. 4b. MCCM effect in a GAA n-MOSFET at $4.2 \mathrm{~K}$.The threshold voltage is swept from the initial low value (1) to the high state (2) by a $V_{B G}=-5 \mathrm{~V}$ pulse. The high state relaxes slowly to the initial value (curve 3 ).

\subsection{GAA p-MOSFETS}

Initial studies of the cryogenic behaviour indicate some unusual effects in GAA p-MOSFETs. At 4.2 K, a reduction of the initial $\mid \mathrm{V}_{\mathrm{T}} \mathrm{T}$ is observed which is opposite to what is found for standard SOI MOSFETs (Fig. 5a). The output curves show a clear hysteresis (Fig. 5b) and the saturation drain current tends to reduce with time. The kink-like feature in the $\mathrm{V}_{\mathrm{GS}}=-1.5 \mathrm{~V}$ curve of Fig. $5 \mathrm{~b}$ is probably related to some 
charge-trapping phenomenon, which is not understood yet. After this, the $I V_{T}$ has increased to a value which is above the room temperature value. Clearly more work is needed to understand these anomalies.

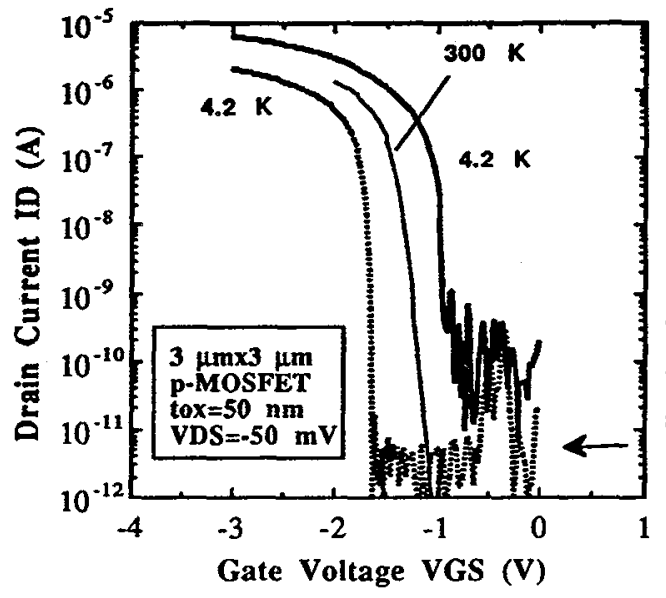

Fig. 5a. Input characteristics of a $3 \mu \mathrm{m} \times 3 \mu \mathrm{m} \mathrm{GAA}$ p-MOSFET at $V_{D S}=-50 \mathrm{mV}$ and $300 \mathrm{~K}$ and $4.2 \mathrm{~K}$. Initial curve (bold line). Dotted line: after $\mathrm{I}_{\mathrm{D}}-\mathrm{V}_{\mathrm{DS}}$ measurement. The shift probably corresponds with the 'kink' in Fig. $5 b$.

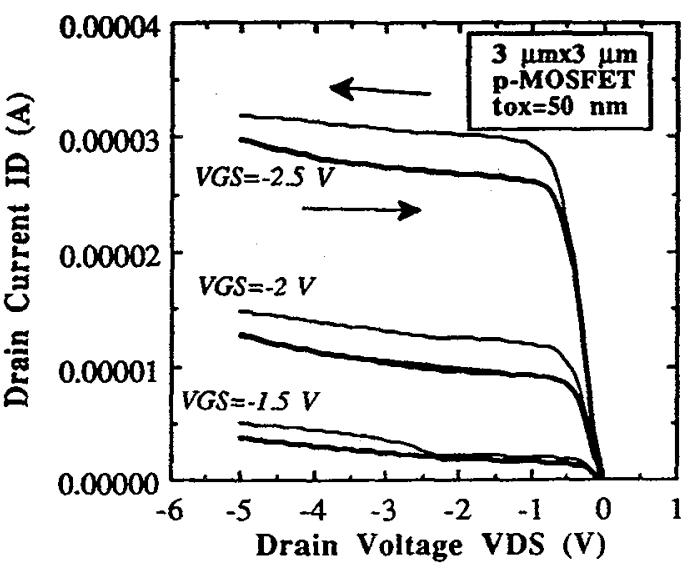

Fig. 5b. Output curves of the same p-MOSFET at $4.2 \mathrm{~K}$, showing clear hysteresis.

\section{CONCLUSION}

The operation of GAA SOI MOSFETs at cryogenic temperatures is demonstrated and confirms the overall superior static parameters compared with conventional devices. However, at $4.2 \mathrm{~K}$ the low $\mathrm{T}$ artefacts are still present to some extent, forming a potential drawback for these applications. On the other hand, one can still make use of the MCCM effect in these transistors, opening up some new potential applications.

\section{References}

[1] Balestra F., Cristoloveanu S., Benachir M., Brini J. and Elewa T., IEEE Electron Device Lett. EDL-8 (1987) 410-412

[2] Hasimoto D., Kaga T., Kawamoto Y. and Takeda E., "A fully depleted lean-channel transistor (DELTA) - A novel vertical ultra thin SOI MOSFET", IEDM Tech. Dig., December 1989 (The IEEE, New York, 1989) pp. 833-836

[3] Venkatesan S., Neudeck G.W. and Pierret R.F., IEEE Electron Device Lett. EDL-13 (1992) 44-46

[4] Suzuki K., Satoh S., Tanaka T. and Ando S., Jpn. J. Appl. Phys. 32 (1993) 4916-4922

[5] Lawrence R.K., Colinge J.P. and Hughes H.L., "Radiation effects in gate-all-around structures", Proc. of the 1991 IEEE Intern. SOI Conf., October 1991 (The IEEE, New York, 1991) pp. 80-81

[6] Colinge J.P. and Terao A., IEEE Trans. Nucl. Sci. NS-40 (1993) 78-82

[7] Simoen E., Claeys C., Coenen S. and Decreton M., Paper submitted for publication in Solid-State Electron.

[8] Claeys C. and Simoen E., "The potential and restrictions of cryogenic SOI technologies", Proc. of the Intern. Symposium on Low Temperature Electronics and High Temperature Superconductivity, Hawaii May 1993, The Electrochem. Soc. Softbound Series vol. 93-22 (The Electrochem. Soc., Pennington-NJ,1993) pp. 109-123 
[9] Colinge J.P., Gao M.H., Romano-Rodriguez A., Maes H. and Claeys C., "Silicon-on-Insulator 'Gate-all-Around' device", IEDM Tech. Dig., December 1990 (The IEEE, New York, 1990) pp 595598

[10] Elewa T., Balestra F., Cristoloveanu S., Hafez I.M., Colinge J.P., Auberton-Herve A.-J. and Davis J.R., IEEE Trans. Electron Devices ED-37 (1990) 1007-1018

[11] Simoen E., Gao M.H., Colinge J.P. and Claeys C., Semicond. Sci. Technol. 8 (1993) 423-428

[12] Francis P., Terao A., Flandre D. and Van de Wiele F., Microelectron. Eng. 19 (1992) 815-819

[13] Terao A., Flandre D., Lora-Tamayo E. and Van de Wiele, F. IEEE Electron Device Lett. EDL-12 (1991) 682-684

[14] Simoen E. and Claeys C.; Paper submitted for publication in IEEE Electron Device Letters

[15] Wang J., Kistler N., Woo J. and Viswanathan C.R., IEEE Electron Device Lett. EDL-12 (1991) 300-302

[16] Simoen E. and Claeys C, J. Appl. Phys. 73 (1993) 3068-3081

[17] Tack M., Gao M.H., Claeys C. and Declerck G., IEEE Trans. Electron Devices ED-37 (1991) 1373-1382

[18] Martino J.A., Rotondaro A.L.P., Simoen E, Magnusson U. and Claeys C., IEEE Trans. Electron Devices ED-40, April 1994. 